\title{
O MODELO DE FEIÇÕES MÍNIMAS, OU DAS UNIDADES ELEMENTARES DE RELEVO: UM SUPORTE CARTOGRÁFICO PARA MAPEAMENTOS GEOECOLÓGICOS
}

Antonio Carlos Colangelo*

\section{RAZÕESTEÓRICASE DE APLICAÇÃODOMODELO}

Em 1989, durante o XIV Congresso Brasileiro de Cartografia, foi apresentado um trabalho preliminar sobre a Carta de Feições Mínimas. Na época, embora seus conceitos básicos já estivessem estabelecidos faltava ainda o aprimoramento da técnica de fotointerpretação, indispensável na elaboração dos exemplos de aplicação com os quais pudemos testar o modelo. Que reapresentamos agora, acrescido de um material cartográfico que serviu para o teste de algumas das hipóteses iniciais de trabalho.

O objetivo original do modelo de Feições Mínimas (Colangelo, 1989) foi produzir um instrumental cartográfico que servisse, ao mesmo tempo, à ciência de base e à ciência aplicada. A idéia central deste modelo é transformar um pedaço de superfície de terreno, uma bacia de drenagem por exemplo, em um equivalente onde toda a complexidade geométrica apresentada pelas formas de relevo possa ser reduzida a nove tipos básicos, a partir dos quais é feito o levantamento morfométrico, ou seja: morfometria controlada por um suporte morfológico.

A realização do objetivo apresentado acima foi orientada por três premissas fundamentais: 1. uma análise morfométrica do terreno (quantitativa) comandada pela análise morfológica (qualitativa); 2 . análise morfológica despojada de elementos descritivos de natureza subjetiva, referente a unidades de relevo cujas formas sejam as mais simples do ponto de vista geométrico, quer dizer, irredutíveis para uma determinada escala de abordagem; 3 . obedecidas as premissas anteriores, elaboração de taxonomia morfológico-morfométrica do relevo, universalmente aplicável, que viabilize a análise comparativa dos diversos sistemas de relevo terrestres.

O modelo aqui apresentado foi inspirado por alguns conceitos e definições apresentados por Hack e Goodlett (1960), Throeh (1965) e Ruhe (1975), que constituem um primeiro referencial teórico a partir do qual desenvolvemos o modelo cartográfico que passaremos a apresentar.
A geometria das formas do relevo, além de regular o comportamento da declividade e da orientação das vertentes, tem uma importante participação no controle dos tipos e da dinâmica dos fluxos hídricos superficiais e sub-superficiais. Isto implica a possibilidade de correlações com uma infinidade de outros fatores e variáveis de naturezas as mais diversas, entre os quais se destacam aqueles ligados à cobertura vegetal e solo.

Considerando verdadeiras as afirmações feitas no parágrafo anterior, os limites das formas do relevo devem separar unidades sistêmicas distintas também do ponto de vista geoecológico, num nível taxonômico que é função da escala de abordagem adotada. Cumpre lembrar também que, uma interpretação correta dos resultados obtidos da aplicação deste método está condicionada à observância de alguns parâmetros fundamentais referentes à área de estudo: clima (zonal, regional, local), embasamento rochoso (litologia e estrutura) e formações superficiais (elúvios, colúvios e alúvios).

Estamos convencidos que a simples sobreposição de uma carta de declividades e uma carta de orientações de vertentes é pouco satisfatória para a realização de uma análise morfométrica do relevo, cujo objetivo é fornecer elementos de interpretação compatíveis à morfologia. Para esclarecer esta afirmação é necessário, em primeiro lugar, verificar o método de confecção destes mapas. Por exemplo, a carta de declividades convencional não se ajusta à geometria do relevo, porque seu traçado obedece a referenciais topográficos (curvas-de-nível) e clinométricos (classes de declividade) pré-estabelecidos. Por isto, nestes mapas, as rupturas de declive e/ou mudanças de forma do terreno geralmente não são registradas, por não coincidirem com o traçado das curvas-de-nível. Quando ocorre, a coincidência, é sempre parcial e acidental. Portanto, o resultado é um mosaico

(*) Professor do Departamento de Geografia da FFLCH/USP. 
de manchas cujos limites topográficos superior e inferior são dados pelo traçado das curvas de nível principais e, os limites laterais, por segmentos retilíneos perpendiculares às mesmas, locados unicamente em função dos limites adotados para as classes de declividades. Do ponto de vista da geometria das formas do terreno os limites das manchas traçadas na carta de declividades convencional são arbitrários.

No caso da carta de orientações de vertente ocorre o mesmo problema. As manchas mapeadas obedecem simultaneamente ao traçado das curvas-de-nivel e às classes de orientações de vertente pré-estabelecidas, não havendo portanto vinculação direta com a geometria das formas de relevo, quer dizer: "unidades geométricas de relevo". Estas foram as razões que me fizeram abandonar a idéia de uma possível interpretação de resultados, a partir da sobreposição das cartas convencionais morfológicas, de declividades e de orientações de vertentes. Sabemos que a validade dos resultados depende da adequação entre os objetivos e a escala de abordagem do trabalho, por isto podemos afirmar que: para escalas de detalhe (1:10.000 e maiores), o método de sobreposição não é adequado quando o objetivo é integrar morfologia e morfometria do relevo, ou seja: gerar uma síntese morfológico-morfométrica do relevo.

A questão acima é fundamental, pois diferentes setores de vertente podem apresentar médias de declividade e/ou orientação equivalentes, apesar de serem superfícies de terreno geometricamente muito distintas. Por exemplo, um setor de alta vertente em frente de interflúvio, "poli-convexo" (convexo em planta e perfil), e outro de baixa vertente em fundo de anfiteatro, "policôncavo" (côncavo em planta e perfil), podem ser, ao mesmo tempo, "homoclinais" e "homodirecionais", entretanto são totalmente distintos no que se refere: à hidrodinâmica de superficie; aos fatores microclimáticos; ao jogo de predominância entre processos exógenos, físicos e químicos; aos tipos de formações superficiais e solos, especialmente no que se refere às variáveis textura e estrutura; e, à composição florística da cobertura vegetal. Em conclusão, tais setores de vertente possuem "status" geoecológicos totalmente distintos, constituindo neste caso, "geótopos" antagônicos.

Uma vez que os métodos aplicados às cartas convencionais de declividades e orientações de vertentes se ocupam unicamente do fator quantitativo (morfometria) em detrimento do fator qualitativo (morfologia), os resultados obtidos a partir destes mapas são pouco significativos do ponto de vista geomorfológico. Estamos convencidos de que a validade metodológica de uma análise morfométrica do relevo depende de sua vinculação a um referencial morfológico consistente, ou seja, fundamentado na "geometria elementar das formas de relevo".

As análises morfológica e morfométrica deverão constituir assim um sistema único, capaz de viabilizar uma interpretação integrada de seus produtos, não só quando se trabalha uma bacia de drenagem ou um sistema de relevo isoladamente, mas também quando for necessário fazer um estudo comparativo entre dois ou mais sistemas de relevo quaisquer.

Quando falamos em "geometria elementar do relevo" nos referimos ao conceito de "unidade geométrica elementar de relevo", ou "feição mínima", que constitui o suporte espacial sobre o qual se apóia o modelo de representação do relevo que passaremos a descrever.

\section{OMODELODE "FEIÇÕESMÍNIMAS"}

A idéia central deste modelo é a de que toda a inumerável variedade de formas de relevo encontradas na superficie da Terra, por mais complexas que possam se apresentar, podem ser reduzidas a um pequeno número de tipos de formas geometricamente simples, ou seja, irredutíveis -para a escala de trabalho adotada. Por esta razão, "feições mínimas", ou "formas elementares", ou ainda, "unidades elementares de relevo", devem ser entendidas como "as formas geometricamente mais simples", identificáveis em sensores remotos e cartas topográficas. Estas unidades devem apresentar área mensurável, segundo a escala adotada, sendo portanto, passíveis de representação cartográfica na forma de implantação zonal (manchas).

Sabe-se que uma imagem das formas de relevo pode ser apreendida da carta topográfica pela interpretação do traçado das suas curvas-de-nível. Estas podem se apresentar retilíneas ou curvilíneas, sendo que, neste último caso podem referir-se a concavidades ou convexidades, conforme o referencial material considerado. As curvas-de-nível e sua equidistância têm a dupla função de fornecer dados altimétricos e uma representação bidimensional do relevo. A partir delas é possível construir uma imagem tridimensional do relevo, tanto mais rica em detalhes quanto maior for a escala de representação utilizada. 
Abrimos aqui um parênteses para esclarecer uma questão epistemológica de fundamental importância: no parágrafo anterior não utilizamos a expressão "aproximação à realidade do terreno" por ser nossa visão de ciência funcionalista o que supõe não estarmos em busca de nenhuma realidade nem verdade que poderia estar escondida por detrás de nosso objeto de estudo. Antes de mais nada, o que nos preocupa é a "coerência interna" e a "validade de aplicação" (coerência externa) do modelo criado a partir de tal objeto, que enxergamos como produto de representação de um elemento (coisa) pertencente à natureza.

Após o esclarecimento acima, vamos descrever ago$\mathrm{ra}$ as idéias fundamentais que nortearam este trabalho. $\mathrm{Na}$ carta topográfica, as inflexões de um grupo de curvas-denível nos fornecem uma idéia das formas do contorno do modelado visto de planta, enquanto o comportamento do espaçamento destas curvas nos dá uma indicação das formas do perfil longitudinal das vertentes. Assim, uma imagem tridimensional das formas do relevo pode ser restituída e interpretada a partir da combinação de duas linhas projetadas, uma para cada um dos planos ortogonais de planta e perfil. A curva-de-nível não é mais que uma seqüência ininterrupta de três tipos de formas geométricas elementares, bidimensionais: convexa, retilínea e côncava. Troeh (1965) apresentou equações tridimensionais para a classificação de superfícies côncavas e convexas, com base em parâmetros obtidos de cartas topográficas. Tais equações, afirma o autor, podem ser úteis na avaliação do escoamento superficial desde que considerados o coeficiente de infiltração e a precipitação. $\mathrm{O}$ autor tinha por objetivo a construção de um modelo hidrológico-matemático e, embora não fizesse referência à cartografia do relevo, sugeria implicitamente a possibilidade de sua cartografação, já que seu modelo tinha sido fundamentado nas formas do relevo. Cumpre lembrar que Troeh não faz referência às formas que apresentam algum tipo de retilineidade incorporada, seja em perfil e/ou planta.

As "feições mínimas" podem também ser definidas como representações de unidades de relevo cujas projeções nos planos ortogonais de perfil e planta exibem, em cada um deles, apenas uma das três formas elementares anteriormente referidas. Sendo assim, são nove as possíveis combinações destas formas. A figura 1 apresenta os nove tipos de unidades elementares de relevo e uma tabela indicando as formas simples bidimensionais a elas associadas. Ruhe (1975) apresenta estes nove tipos geométricos básicos e suas relações com os fluxos de superfície, agrupandoos em função do que definiu por "grau de complexidade dos fluxos". Entretanto, não apresenta uma integração destes tipos de formas num sistema taxonômico que incluísse a representação cartográfica do relevo.

\section{Figura 1 : Unidade Ideal de Relevo e suas Componentes Elementares}

\begin{tabular}{|c|c|c|}
\hline \multicolumn{3}{|c|}{ Feições Mínimas } \\
\hline Tipos & \multicolumn{2}{|c|}{ Formas } \\
\hline Número & Perfil & Planta \\
\hline 1 & CV & CV \\
\hline 2 & CV & RET \\
\hline 3 & CV & CC \\
\hline 4 & RET. & CV \\
\hline 5 & RET. & RET. \\
\hline 6 & RET. & CC \\
\hline 7 & CC & CV \\
\hline 8 & CC & RET. \\
\hline 9 & CC & CC \\
\hline
\end{tabular}

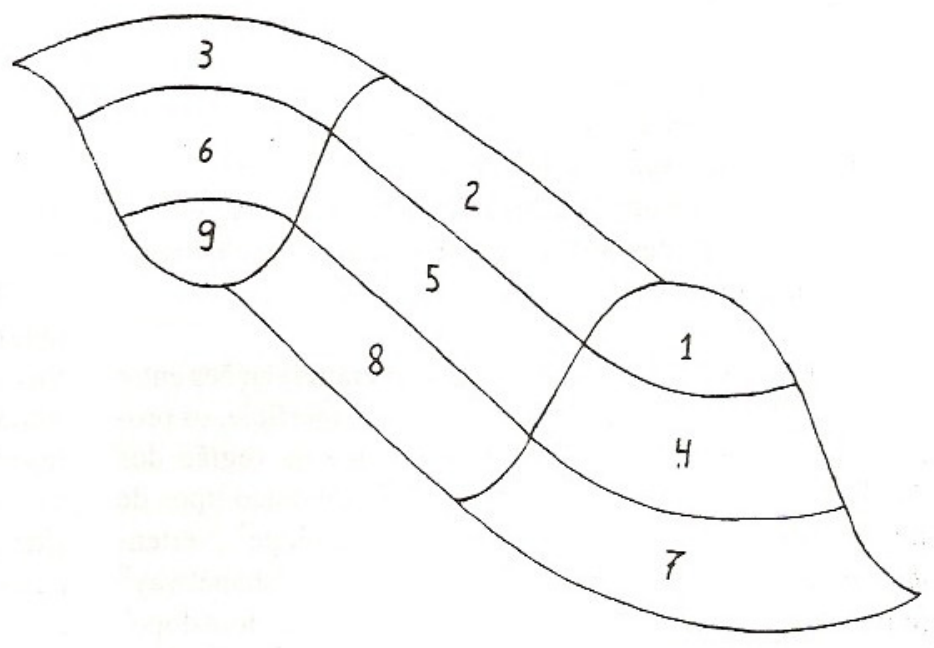

$\mathrm{CV}=$ convexo; $\mathrm{RET}$ = retilíneo; $\mathrm{CC}=$ côncavo 
O relevo continental é constituído por uma sucessão de elevações e depressões que são construídas tectonicamente e esculpidas pela ação combinada de processos erosivos vinculados tanto ao escoamento superficial fluvial (linear) quanto ao escoamento interfluvial (em lençol e/ou linear), excluídas aqui as áreas glaciais, as áreas desérticas e as de atividade vulcânica intensa. No tempo geológico, foram as persistentes ações erosivas, físicas e químicas, das águas de superfície e subsuperfície sobre o arcabouço litotectônico, as responsáveis pela esculturação de grande parte de toda a variedade de formas de relevo presentes na atualidade. E claro, não podemos esquecer das ações erosivas do gelo continental, dos ventos e das águas oceânicas, bem como aquelas vinculadas aos organismos vivos em geral e ao homem em particular.

A aparente complexidade geométrica exibida pelo modelado terrestre pode ser entendida como o produto da justaposição, com repetição exaustiva, dos nove tipos de "unidades elementares de relevo" acima referidas. Portanto, é possível através da identificação e delimitação destes nove tipos, decompor toda a superfície do terreno em unidades morfológicas, sobre as quais serão medidas a área e as médias das declividades e orientações das vertentes. A partir destes dados computados é possível, por agrupamento das unidades elementares de mesmo tipo, recompor e representar o relevo de uma dada área através de um modelo correspondente à sua síntese estatística, quer dizer: toda a aparente complexidade morfológica exibida pela superficie mapeada é reduzida aos nove tipos elementares de formas, mantida a proporcionalidade em área para cada tipo mapeado.

Assim, neste processo de modelização, o relevo de toda a área mapeada pode ser reduzido a uma unidade geomórfica análoga a um par antagônico "frente-deinterflúvio - anfiteatro" construído a partir dos resultados estatísticos referentes aos nove tipos de formas elementares, ou feições mínimas.

Hack e Goodlett (1960) estabeleceram relações entre as formas do relevo, a hidrodinâmica de superfície, os processos erosivos e a composição florística na região dos Apalaches Centrais, a partir da definição de cinco tipos de formas: "nose" (alto dos interflúvios), "side slope" (vertentes laterais), "hollow" (fundo dos anfiteatros), "shanelway" (curso de escoamento superficial concentrado) e "footslope" (correspondente às áreas de transição entre vertentes laterais e canal fluvial). $\mathrm{O}$ modelo apresentado pelos autores neste clássico artigo, seguramente um dos mais citados no que se refere à Geomorfologia americana, foi um referencial importante para este trabalho.

\section{FORMASELEMENTARESE HIDROLOGIA DE SUPERFÍCIE}

Considerando a escala de um perfil de vertente, a dinâmica dos fluxos hídricos superficiais é controlada fundamentalmente por dois fatores: o primeiro deles condiciona a energia cinética transferida aos fluxos, referindo-se portanto à atuação da componente lateral da força gravitacional, que é por sua vez controlada pela declividade do terreno; 0 segundo, controla o padrão espacial do escoamento através da geometria do terreno, subordinando o.comportamento das linhas de fluxo.

Os padrões de drenagem do escoamento superficial interfluvial podem ser descritos em função do caráter de dispersão ou concentração a eles vinculados. Estes padrões, por serem controlados pela geometria do terreno, devem ser analisados a partir das formas projetadas nos planos ortogonais de perfil e planta. Neste caso, a convexidade e a concavidade das formas de relevo são os fatores que condicionam, respectivamente, os padrões de dispersão e concentração de drenagem. Por esta linha de raciocínio, devemos associar à retilineidade das formas a neutralidade dos fluxos hídricos, quer dizer: não há dispersão nem concentração de drenagem no que diz respeito ao condicionante geométrico.

Quanto à convexidade das formas de relevo, quando observada em planta, condiciona linhas de fluxo divergentes por aumento da superfície de escoamento em direção à jusante, como ocorre numa frente de interflúvio. Podemos denominar esta componente de dispersão dos fluxos de "dispersão radial". Já, a convexidade observada em perfil define outra componente de dispersão, vinculada à energia dos fluxos. Uma vez que os perfis convexos das vertentes determinam um aumento progressivo de declividade para a jusante, a componente lateral da força de gravidade aumenta e, conseqüentemente, acelera o fluxo de superfície. Considerando que, neste caso, a força resultante ligada às partículas de água é tangencial à superfície convexa do terreno, a água seria como que forçada a se desprender pela tangente. Isto define uma "tendência" a menor retenção d'água na superfície do terreno e, portanto, menores montantes dispo- 
níveis para a percolação e abastecimento do lençol subterrâneo. Entretanto, deve-se salientar que os setores convexos de alta vertente estão geralmente associados a solos com menores teores de argila do que os pertencentes aos setores côncavos basais, principalmente quanto ao horizonte $\mathrm{B}$, o que corresponde a maior permeabilidade $\mathrm{e}$ condutividade hidráulica. Isto tende a compensar, em parte, o fator de dispersão acima descrito.

Portanto, existem duas componentes de dispersão vinculadas à geometria do relevo: uma, imposta pelo aumento progressivo da superfície de escoamento disponível a jusante (dispersão radial); outra, refere-se à aceleração dos fluxos através da ação de uma força tangencial à superfície do terreno (dispersão longitudinal). A primeira componente, ligada à convexidade das formas em planta, tende a provocar uma diminuição progressiva da disponibilidade de água por unidade de área, por espalhamento. A segunda, ligada à convexidade em perfil, dificulta a retenção superficial da água e, conseqüentemente, tende a reduzir os seus montantes disponíveis para a percolação. Quanto aos padrões de escoamento superficial interfluvial vinculados às formas côncavas do relevo - concentração de drenagem o raciocínio segue na mesma direção, porém no sentido oposto.
Foi a partir das relações entre geometria do relevo e hidrodinâmica de superfície que, a cada um dos nove tipos de formas elementares fềz-se corresponder um padrão específico de escoamento superficial. Os nove padrões resultantes foram organizados em dois níveis taxonômicos: o primeiro nível estabelece o DOMÍNIO HIDRODINÂMICO a que pertence um dado padrão, enquanto que o segundo especifica o seu tipo dentro do domínio. Com base neste procedimento, foram estabelecidos três domínios hidrodinâmicos, a saber: o DOMÍNIO DE DISPERSÃO, no qual estão incluídos os fluxos hiperdispersores, mesodispersores longitudinais, hipodispersores e mesodispersores radiais, respectivamente vinculados às formas elementares dos tipos $1,2,3$ e 4; o DOMÍNIO DE TRANSIÇÃO (ou de NEUTRALIDA$\mathrm{DE})$, vinculado à forma elementar do tipo 5 e fluxo "neutro"(paralelismo das linhas de fluxo); e, o DOMÍNIO DE CONCENTRAÇÃO, que inclui os fluxos mesoconcentradores radiais, hipoconcentradores, mesoconcentradores longitudinais, e hiperconcentradores, respectivamente vinculados às formas elementares $6,7,8, \mathrm{e}$ 9. Nesta classificação os padrões de fluxo se ordenam numa gama de níveis, entre as condições extremas de hiperdispersão e hiperconcentração de drenagem, passando pela condição intermediária de transição ou neutralidade (figs. $1 \mathrm{e} 2$ ).

Figura 2: Quadro de Classificação dos fluxos hídricos superficiais

\begin{tabular}{|c|c|c|c|c|}
\hline FM & Perfil & Planta & Fluxo Resultante & Domínio \\
\hline 1 & $\mathrm{CV}$ & $\mathrm{CV}$ & Hiperdispersor & \multirow{4}{*}{ Dispersão } \\
\hline 2 & $\mathrm{CV}$ & r & Mesodisp. Longitudinal & \\
\hline 3 & $\mathrm{CV}$ & $\mathrm{CC}$ & Hipodispersor & \\
\hline 4 & $\mathrm{r}$ & $\mathrm{CV}$ & Mesodisp. Radial & \\
\hline 5 & r & $\mathrm{r}$ & Transição (Neutro) & Transição \\
\hline 6 & $\mathrm{r}$ & $\mathrm{CC}$ & Mesoconc. Radial & \multirow{4}{*}{ Concentração } \\
\hline 7 & $\mathrm{CC}$ & $\mathrm{CV}$ & Hipoconcentrador & \\
\hline 8 & $\mathrm{CC}$ & $\mathrm{r}$ & Mesoc. Longitudinal & \\
\hline 9 & $\mathrm{CC}$ & $\mathrm{CC}$ & Hiperconcentrador & \\
\hline
\end{tabular}


Por serem definidas a partir de uma homogeneidade de caráter fundamentalmente geométrico, as unidades elementares de relevo devem exibir uma constância, ou regularidade, no que se refere ao comportamento de suas variáveis morfométricas elementares: declividade e orientação das vertentes. Obviamente a idéia de constância e regularidade inclui também a condição de não variação.

Dentro desta linha de raciocínio, as formas elementares de relevo têm sempre seus limites marcados por rupturas, sejam elas de VALOR ou de COMPORTAMENTO, tanto no que se refere à declividade, quanto à orientação das vertentes. Ruptura significa aqui uma quebra brusca de valor e/ ou ritmo de variação, no espaço, de um determinado elemento morfométrico. Se percorrermos a extensão de uma unidade elementar de relevo vamos detectar, na maior parte dos casos, uma variação de declividade e/ou orientação da vertente no terreno, com exceção apenas das unidades planas do tipo 5, que apresentam retilineidade nas duas projeções ortogonais de planta e perfil. Foram estas as razões que nos levaram a incluir as variáveis declividade e orientação das vertentes no quadro taxonômico das "feições mínimas", cuja tipologia de comportamento pode ser sintetizada da seguinte maneira:
FEIÇÕES MULTICLINAIS: são aquelas que apresentam variação de declividade (V.D.), podendo esta ser positiva, quando associada à convexidade (+V.D.), ou negativa, quando associada à concavidade das formas elementares na projeção em perfil (-V.D.).

FEIÇÕES MULTIDIRECIONAIS: são aquelas que apresentam variação de orientação (V.O.), podendo esta ser positiva, se associada à convexidade (+V.O.), ou negativa, se associada à concavidade das formas elementares na projeção em planta (-V.O.).

FEIÇÕESMONOCLINAISEMONODIRECIONAIS: são aquelas onde não há variação apreciável de declividade $(\mathrm{VD}=0)$, nem de orientação $(\mathrm{VO}=0)$, o que se deve à retilineidade das formas elementares, respectivamente nas projeções ortogonais de perfil e planta.

Nas figuras 3 e 4 são apresentados dois quadros sobre o COMPORTAMENTO CLINO-DIRECIONAL das vertentes por tipo de forma de relevo, sua classificação e a distribuição (teórica) em área para cada tipo. Estes quadros referem-se a uma célula hipotética de relevo, ideal portanto, e cuja distribuição das formas elementares pode ser considerada modelar ou padrão.

Figura 3: Quadro da Distribuição Teórica dos Elementos Cinométricos e Direcionais

\begin{tabular}{|c|c|c|c|c|c|}
\hline Classificação & FM & $\underset{\%}{\mathrm{MC}}$ & $\underset{\%}{N C}$ & $\underset{\%}{\mathrm{MD}}$ & $\underset{\%}{\mathrm{ND}}$ \\
\hline \multirow{2}{*}{$\begin{array}{l}\text { Multiclino- } \\
\text { direcionais }\end{array}$} & 1 e 9 & 22,2 & & 22,2 & \\
\hline & 3 e 7 & 22,2 & & 22,2 & \\
\hline $\begin{array}{c}\text { Multiclino- } \\
\text { monodirecionais }\end{array}$ & 2 e 8 & 22,2 & & & 22,2 \\
\hline $\begin{array}{l}\text { Monoclino- } \\
\text { multidirecionais }\end{array}$ & 4 e 6 & & 22,2 & 22,2 & \\
\hline $\begin{array}{l}\text { Monoclino- } \\
\text { direcional }\end{array}$ & 5 & & 11,2 & & 11,2 \\
\hline $\begin{array}{l}\text { Área Total } \\
\text { (Teórica) \% }\end{array}$ & & 66,6 & 33,4 & 66,6 & 33,4 \\
\hline $\begin{array}{l}\mathrm{FM}=\text { feiçoes mínimas } \\
\mathrm{MC}=\text { multiclinal } \\
\mathrm{ND}=\text { monodirecional }\end{array}$ & \multicolumn{5}{|c|}{$\begin{array}{l}\mathrm{NC}=\text { monoclinal } \\
\mathrm{MD}=\text { multidirecional }\end{array}$} \\
\hline
\end{tabular}


Figura 4: Elementos Clino-direcionais do Modelo de Feições Mínimas
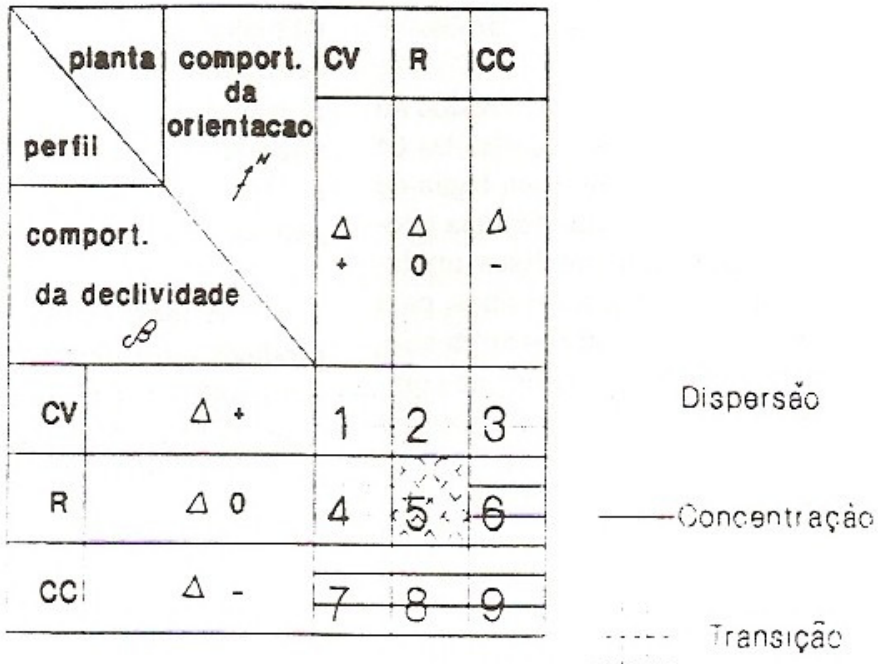

Para uma distribuição padrão como a apresentada nos quadros referentes às figuras $3 \mathrm{e} 4$, verificamos que: os fatores multiclinal e multidirecional são duas vezes mais expressivos em área que os monoclinais e monodirecionais, e; os domínios de DISPERSÃO e de CONCENTRAÇÃO de drenagem interfluvial são, cada um, quatro vezes mais expressivos em área que o domínio de TRANSIÇÃO. Este último poderia também receber a denominação de domínio de "neutralidade", ou paralelismo dos fluxos hídricos superficiais. A opção pela denominação "DOMÍNIO DE TRANSIÇÃO" deve-se ao fato deste ser, do ponto de vista funcional, um domínio de CONEXÃO interposto entre os outros dois, que constituem um par antagônico.

Obviamente, os relevos de porções reais de terreno, quando mapeados, devem apresentar desvio em relação à DISTRIBUIÇÃO PADRÃO (teórica). Daí a importância de usá-la como referencial estatístico quando se deseja fazer um estudo comparativo entre relevos de distintas áreas. Como por exemplo, quando se quer fazer um estudo morfológico-morfométrico comparado entre relevos vinculados a duas ou mais bacias de drenagem quaisquer, sejam elas de mesma ordem de grandeza ou não. Neste caso, a distribuição padrão, ou teórica, a que nos referimos constitui o suporte fundamental para a efetivação de tal comparação.

Quando nos referimos à distribuição padrão das unidades elementares de relevo não estamos alimentando ne- nhuma idéia assimilável ao conceito de "relevo normal". O referencial teórico é fundamental neste caso porque o modelo, no que concerne à geometria das formas, é dedutivo por excelência.

Em resumo, o modelo apresentado propõe uma taxonomia do relevo apoiada na geometria das formas (morfologia) e suas relações com os comportamentos: das variáveis morfométricas elementares declividade e orientação das vertentes, e; dos fluxos hídricos vinculados à drenagem superficial interfluvial (padrões de drenagem).

Pode-se, a título de ilustração, estabelecer uma analogia entre o "modelo das feições mínimas" e o modelo da estrutura da matéria apresentado pela Física. Do mesmo modo que um número incalculável de moléculas é gerado a partir da combinação de um pequeno número de átomos, os inumeráveis tipos de formas de relevo (complexas), exibidas pela rede interfluvial, podem ser interpretados como diferentes arranjos entre apenas nove tipos de unidades elementares de relevo. Neste sentido, uma "molécula de relevo" corresponde a um par antagônico "frente de interflúvio - anfiteatro" (elevação-depressão), que por sua vez é composto por "átomos de relevo" referentes às "feições mínimas", ou unidades geométricas elementares de relevo. Grandes conjuntos de "moléculas de relevo", de um ou mais tipos, comporiam assim os diferentes "sistemas de relevo", que por seu turno comporiam os inumeráveis compartimentos topomorfológicos. Estes "sistemas de relevo" poderiam 
também ser assimilados por analogia à grande diversidade de tecidos celulares encontrada nos organismos vivos, que da mesma maneira exibem diferentes texturas e arranjos.

Entendemos que a vantagem deste modelo reside no fato de permitir a desintegração de todas as "moléculas de relevo" de uma área mapeada, por exemplo uma bacia de drenagem, em unidades irredutíveis do ponto de vista geométrico, dada a escala de abordagem adotada. Estas unidades podem ser reagrupadas, segundo seus nove tipos, para compor um par antagônico frente de interflúvio- anfiteatro, estatisticamente representativo de todos os pares que compõem o relevo da área de estudo. Portanto, com a aplicação deste método é possível reduzir o relevo a uma unidade modelar, que fornecerá os parâmetros espaciais necessários à pesquisa quantitativa, sobre uma infinidade de variáveis ligadas ao meio fisico terrestre.

Os quadros taxonômicos apresentados (figs. 1,2,3 e 4) referem-se a entidades teóricas, razão pela qual são fundamentalmente dedutivos, ordenados a partir de uma análise apoiada no fator geométrico e suas implicações no que concerne à classificação e cartografia do relevo terrestre.

A "carta de feições mínimas" é consequiência imediata do modelo acima apresentado. Ambos, modelo e mapa, fazem parte de um corpo único, porque são elementos complementares e interdependentes. Em outras palavr $s$ s, os problemas de aplicação condicionaram a construção do modelo, da mesma maneira que o modelo condicionou o tipo de solução apresentado.

Para a elaboração da carta de feições mínimas foram utilizados mapas topográficos na escala de 1:10000, e fotografias aéreas, na escala de 1:25000. Houve controle de campo dos trabalhos de interpretação e medição realizados sobre a carta topográfica e da fotointerpretação. $\mathrm{O}$ exame estereoscópico das fotos aéreas bem como o trabalho de fotointerpretação foram de inestimável ajuda no controle dos produtos obtidos a partir da carta topográfica. A carta de feições mínimas é, ao mesmo tempo, um mapa de formações superficiais, um mapa morfológico e um mapa morfométrico. Do ponto de vista morfométrico é possível elaborar seja um mapa de orientação de vertentes, seja um mapa de declividades, sempre com base no referencial morfológico, quer dizer, sempre a partir do suporte dado pelas unidades elementares de relevo - "feições mínimas".

Os mapas de "formações superficiais" e "morfológico - feições mínimas" - são mapas-base, ou mapas-suporte, a partir dos quais podem ser elaborados os mapas morfométricos (segunda geração) bem como toda uma gama de mapas de aplicação (terceira geração). Dentro desta terceira categoria podemos citar: mapas da dinâmica superficial e subsuperficial dos fluxos hídricos; mapas de potencial e risco erosivo, por modalidade de erosão; mapas de prognóstico de evolução do relevo e, até mesmo, mapas geoecológicos.

A idéia central deste modelo cartográfico foi a de produzir um suporte morfológico sobre o qual se pudesse implantar uma Cartografia que poderíamos chamar de "Cartografia Multi-Uso". Que fosse capaz de atender algumas das necessidades de aplicação de determinados setores das "Ciências da Terra", como por exemplo: a Géomorfologia, a Pedologia, a Geoecologia, a Biogeografia, a Microclimatologia, e mesmo a Sedimentologia.

A hipótese central de trabalho referente a este modelo é a seguinte: a análise QUANTITATIVA deve estar subordinada ao fator QUALITATIVO, quer dizer, a MORFOLOGIA precede e regula a MORFOMETRIA na medida que esta última não tem relevância interpretativa em si mesma e depende de um referencial teórico qualitativo, que acreditamos, deve ser suprido por uma teoria fundamentada na morfologia. Neste caso a teoria estatística nos serve unicamente como uma ferramenta de trabalho capaz de parametrizar o comportamento das variáveis medidas, não sendo possível produzir interpretações e conclusões sem que seus resultados sejam apreciados a partir do referencial morfológico.

As questões até aqui tratadas foram exclusivamente referentes à manutenção da coerência interna do modelo. São, portanto, questões de "validade" e não questões de "verdade". A seguir, serão descritos os procedimentos adotados na solução de problemas de ordem operacional vinculados à confecção da carta e sua aplicação.

\section{CONFECÇÃODOMAPA DE "FEIÇÕES MÍNIMAS"}

$\mathrm{Na}$ carta topográfica, com o auxílio das fotografias aéreas e do controle de campo da fotointerpretação, foi possível delimitar, na primeira etapa do trabalho, quatro conjuntos de formações superficiais: elúvios, colúvios, colúviosalúvios e alúvios, ou seja; materiais de vertente autóctones, materiais de vertente mobilizados, depósitos de vertente 
mesclados com depósitos fluviais e depósitos exclusivamente fluviais. Desta maneira, o primeiro nível de cartografação corresponde a um mapa das "Formações Superficiais", a partir do qual será feito o mapa morfológico que fornece ao mesmo tempo, referencial para as medidas morfométricas e suporte teórico para a interpretação dos dados referentes a estas medidas.

Após a separação dos tipos de "Formações Superficiais" delimita-se o "DOMÍNIO DE DISPERSÃO HÍDRICA INTERFLUVIAL NOS MATERIAIS ELUVIAIS", através de uma linha contínua. Desta maneira, topos, colos, patamares e frentes de interflúvio são agrupados numa grande mancha digitada, geralmente contínua, com um padrão similar ao da rede formada pelas linhas de divisores d'água. Este padrão apresenta-se como o negativo da rede de drenagem fluvial.

O traçado da linha de separação do "DOMÍNIO HIDRODINÂMICO DE DISPERSÃO" na carta topográfica, é realizado de modo que a mancha por ela delimitada contenha: a) todos os setores convexos (em planta)de um conjunto de curvas de nível; b) os setores retilíneos de um conjunto de curvas de nível (em planta), cujo padrão de espaça-mento por elas exibido seja progressivamente menor, de montante para jusante (perfil convexo), ou; c) o setor retilíneo da curva correspondente ao nível topográfico maior, ou seja, mais próximo ao divisor de águas, quando o padrão de espaçamento descrito no caso anterior não for identificado.

Na situação "a", que inclui as frentes de interflúvio, a linha de separação entre domínios hidrodinâmicos traça entre as curvas de nível uma diagonal que progride para uma perpendicular, cruzando-as nos pontos onde as curvas passam de convexas a retilíneas, ou ainda, diretamente de convexas a côncavas até que, próximo ao nível topográfico inferior referente à frente de interflúvio delimitada, a mesma linha de separação volta a traçar uma diagonal que progride para uma paralela que, eventualmente pode sobrepor-se à curva de nível correspondente a tal cota. Nas situações "b" e "c", respectivamente, a linha de separação tende a sobrepor-se ao trecho retilíneo, seja da curva de nível na base do setor de perfil convexo de topo de vertente - que marca a mudança de comportamento do espaçamento entre os conjuntos de curvas -, seja daquela mais próxima ao divisor. No que diz respeito a este último caso ("c"), a correção do traçado depende tanto do exame estereoscópico das fotos aéreas, quanto do conhecimento prévio de campo dos sistemas de relevo pertencentes à área mapeada.
O isolamento inicial do domínio de dispersão (linha cheia) simplifica o trabalho subseqüente de delimitação das "UNIDADES GEOMÉTRICAS ELEMENTARES DERELEVO" (linha tracejada).

Como já havíamos exposto anteriormente, o traçado das "feições mínimas" refere-se à interpretação de "RUPTURAS" de comportamento e/ou valor numérico das variáveis morfométricas elementares: declividade e orientação das vertentes. Tais rupturas correspondem a mudanças significativas de: 1) comportamento da declividade e/ou; 2) valor numérico da declividade e/ou; 3) comportamento da orientação e/ou; 4) valor numérico da orientação das vertentes. Deve-se salientar que a expressão "MUDANÇA SIGNIFICATIVA" é equivalente à expressão "MUDANÇA DETECTÁVEL", ou seja, está vinculada à escala de representação do relevo adotada.

Quanto à variável declividade, casos 1 e 2, deve ser medido e interpretado o comportamento do espaçamento apresentado por um conjunto de curvas de nível, preferencialmente de montante para jusante, seguindo a linha de maior declive, transversal às curvas de nível. Nestes dois primeiros casos definem-se os limites superior e inferior de traçado das "feições mínimas". Já, em relação à variável orientação das vertentes, casos 3 e 4 , deve ser medido e interpretado o comportamento do traçado exibido por um conjunto de curvas de nível e suas inflexões. Nestes dois últimos casos são estabelecidos os limites topográficos laterais do traçado das feições mínimas.

No primeiro caso, a importância da análise do comportamento exibido pelo espaçamento entre as curvas de nível deve-se à propriedade que este tem de fornecer uma imagem do comportamento da declividade que, por sua vez, determina a forma do perfil das vertentes, que é uma das duas componentes vinculadas às "unidades elementares de relevo". Desta maneira, de montante para jusante, um conjunto de curvas de nível pode apresentar os seguintes padrões de espaçamento: 1a) progressivamente menor - perfil convexo; $1 \mathrm{~b}$ ) regular (inclui microvariações positivas e negativas) - perfil retilíneo, ou; 1c) progressivamente maior perfil côncavo. Nestes casos a linha que separa um tipo de forma elementar de outra, pode corresponder simplesmente a uma ruptura de comportamento da variável declividade, $\mathrm{e}$ não necessariamente a uma mudança brusca do seu valor numérico (ruptura de declive). Portanto, a linha de contato pode separar setores de perfil de vertente geometricamente 
distintos (convexo-retilíneo, retilíneo-côncavo, convexocôncavo) e/ou setores limitados por rupturas de declive propriamente ditas. Por exemplo, na carta topográfica a transição de um setor convexo de vertente para outro retilíneo pode corresponder apenas à interrupção do aumento progressivo da declividade, podendo esta atingir um determinado valor, no seguimento convexo, e neste valor permanecer por toda a extensão do seguimento retilíneo subsequente, não havendo portanto, ruptura de declive detectável. Neste caso, a linha de contato indica unicamente a presença de ruptura no comportamento da declividade o que, na prática, ocorre com frequência.

No segundo caso, as rupturas de declive propriamente ditas, ou rupturas de valor numérico da declividade, podem ou não separar segmentos de perfil de vertente geometricamente distintos. Não é tão raro o registro de rupturas de declive entre segmentos de vertente de mesma natureza geométrica (convexo-convexo, retilíneo-retilíneo, côncavocôncavo). Nestes casos temos uma mudança brusca de valor de declividade, apesar do espaçamento entre as curvas de nível apresentar um padrão similar, a montante e a jusante da ruptura de declive. Por exemplo, um setor de vertente côncavo caracterizado, na carta topográfica, por um padrão de espaçamento progressivamente maior entre as curvas, pode ser interrompido bruscamente e, em seguida, exibir o mesmo padrão. Neste caso é necessário separar as duas unidades porque, se não diferem quanto à sua natureza morfológica, devem diferir quanto à caracterização morfometrica, e, mesmo que fossem perfeitamente iguais ainda assim seriam duas e não uma unidade elementar de relevo.

Cumpre lembrar que a aparente anomalia acima descrita vincula-se à questão da escala de representação adotada. Utilizamos neste caso a expressão aparente anomalia porque, rigorosamente, considerando os sistemas de relevo naturais, deve haver sempre algum segmento convexo unindo dois segmentos côncavos de vertente, por mais diminuto e restrito que ele seja. Ocorre que este setor convexo de conexão, pode ter amplitude topográfica muito menor do que aquela correspondente à eqüidistância das curvas de nível da carta topográfica, não havendo portanto, possibilidade de registro desta informação na escala de representação adotada. Entretanto, elementos morfológicos desta magnitude podem ser visualizados nas fotografias aéreas, graças à elevada resolução de imagem apresentada pelo material fotográfico, mesmo quando dispomos de fotos cuja escala seja menor que a dos mapas topográficos.
Devemos salientar que o problema da escala de abordagem e representação do objeto de estudo a que nos referimos acima é antes de mais nada universal e permanente no que concerne ao conhecimento científico no seu sentido mais amplo. Em hipótese nenhuma constitui um problema exclusivo da Geografia, embora sejam os geógrafos aqueles que mais enfatizam este problema da escala de abordagem.

Nos terceiro e quarto casos, as rupturas de comportamento e/ou valor numérico da orientação das vertentes são analisadas, em parte, a partir dos critérios técnicos habitualmente adotados na confecção de cartas de orientação de vertentes (De Biasi et alli, 1977). Entretanto, estas medidas são aqui controladas principalmente pelas já referidas rupturas de traçado das curvas de nível (inflexões) e não a partir de classes de orientação pré-estabelecidas, como ocorre na confecção das cartas de orientação de vertentes convencionais. Como, neste caso o objeto de representação, medição, análise e interpretação refere-se às unidades geométricas elementares do relevo, as medidas, sejam elas de declividade ou de orientação das vertentes, devem expressar os valores médios registrados em cada uma das unidades traçadas na carta topográfica.

Só após o registro, os valores médios a que nos referimos acima serão então plotados em classes de declividades (9 classes) e de orientações de vertente ( 9 classes). Esta é uma questão metodológica central e distintiva no que se refere à concepção deste modelo de representação do relevo: nele, as classes de declividades e de orientações das vertentes não condicionam o mapeamento, que é regido unicamente pelo fator morfológico, nos diferentes tipos de formações superficiais.

Concretamente, no caso presente foram estabelecidas nove classes de declividade com as seguintes amplitudes: 1 (0-5), 2 (6-10), 3 (11-15), 4 (16-20), 5 (21-25), 6(26-30), 7 (31$35), 8(36-45), 9(>45)$. Os critérios adotados na definição das amplitudes de classe foram norteados: pelos valores de declividade encontrados na área de estudo; pelos limiares de declividade obtidos a partir de ensaios de campo sobre a resistência ao cisalhamento; e, por alguns dos valores fixados pela legislação vigente no país, no que tange às questões de proteção ambiental.

Quanto à orientação das vertentes, foram adotadas oito classes (N,NE,E,SE,S,SW,W,NW), mais uma referente aos casos onde unidades de relevo posicionadas no alto dos interflúvios ou nos fundos de vale, apresentam valores 
de declividade tão baixos (0-5) que os condicionantes microclimáticos associados à orientação das vertentes (grau de insolação, ventos e chuva) são irrelevantes. As unidades de relevo que apresentam estas características foram denominadas omnidirecionais.

No caso das unidades de relevo multidirecionais (dos tipos 1,4,7 e 3,6,9 fg.3), quando estas apresentam amplitude direcional superior a 1,5 vezes a amplitude de classe (45 graus), devem ser subdivididas em unidades menores. Por exemplo, uma porção de relevo referente ao que Ab'Saber denominou de morro mamelonado, cujo atributo morfológico principal é a policonvexidade (Prof. Libault), será representado na carta de feições mínimas por um conjunto de unidades adjacentes do tipo 1 . O traçado dos limites laterais é determinado neste caso apenas pelos limites das classes de orientação das vertentes, não havendo ruptura seja de comportamento, seja de valor numérico da orientação. $O$ que se tem é uma variação regular de orientação ao longo de uma mesma unidade geométrica de relevo, suficientemente ampla para abarcar mais de uma classe de orientação. $\mathrm{Na}$ verdade os limites de classes das orientações de vertentes irão condicionar unicamente a subdivisão de uma mesma grande unidade elementar de relevo.

Cada unidade de relevo traçada na carta de feições mínimas aparece acompanhada de um código numérico de três dígitos: o primeiro pode assumir valores de 1 a 9 correspondentes aos tipos de formas elementares; o segundo dígito indica a orientação média, podendo assumir valores de $0 \mathrm{a} 8 \mathrm{e}$, finalmente; o terceiro dígito refere-se às classes de declividades de 1 a 9 às quais nos referimos acima.

\section{HORIZONTESDE APLICAÇÃOE LIMITAÇÕESDOMODELO}

Por mais específicas que tenham sido as razões teóricas e práticas responsáveis pela elaboração do modelo de feições mínimas, estamos certos de que ele pode ser útil não só aos geomorfólogos, como também aos profissionais das Ciências da Terra em geral. Esta convicção é sustentada pela hipótese principal que levou à elaboração do modelo $\mathrm{e}$ que tem por base a seguinte questão: existe um índice de correlação satisfatório entre o tipo de geometria do relevo e os elementos componentes do meio físico, considerada a escala de abordagem? Tal correlação estaria condicionada à dinâmica e tipologia dos fluxos de energia e matéria, super- ficiais e subsuperficiais, os quais são regulados, direta ou indiretamente, pelo comportamento das variáveis topomorfológicas vinculadas à geometria do relevo?

Estamos, a princípio, inclinados a responder positivamente a estas questões porque a dinâmica e tipologia dos fluxos hídricos regula, em elevado grau, a dinâmica e tipologia dos processos físicos e químicos. A partir destas premissas existe uma expectativa positiva sobre a existência de um índice de correlação satisfatório entre as unidades elementares de relevo e a distribuição dos tipos: de formações superficiais (elúvios, colúvios e alúvios); de arranjo dos volumes pedológicos, e; de cobertura vegetal. Isto para citar alguns dos elementos principais, ou de primeira ordem, referentes aos sistemas naturais.

Em síntese, a carta de feições mínimas é, ao mesmo tempo, um mapa: morfológico, de declividades, de orientação das vertentes e da tipologia dos fluxos hídricos de superfície. Por integrar variáveis de diversas naturezas num referencial morfológico universal, estamos convencidos que este instrumental pode ser aplicado não só à Geomorfologia, como também à Pedologia, Geologia, Hidrologia, Biogeografia, Microclimatologia, Agronomia, Engenharia Civil e Florestal, Ecologia e Arqueologia. É muito grande o número de relações e correlações que se pode procurar estabelecer entre os dados morfológico-morfométricos, espacializados na carta de feições mínimas, e os diversos elementos que compõem o meio físico terrestre. Estamos convencidos também de que este instrumental pode servir de base para a cartografia geoecológica de detalhe.

Em contrapartida às vantagens acima referidas, o modelo ainda encontra alguns obstáculos de ordem operacional a serem vencidos para que possa ser sistematicamente utilizado na pesquisa aplicada. A elaboração da "carta de feições mínimas" é ainda artesanal, o que implica estar o bom resultado do mapeamento subordinado, em grande parte, às habilidades de fotointerpretação do executor. Por maior que seja sua eficácia ele estará sempre sujeito às limitações humanas no que concerne ao trabalho repetitivo e sistemático. Esperamos, para um futuro próximo, que estes mapas possam ser traçados por computador. Evans (1980) apresenta dois mapas elaborados por computador, referentes à bacia de Ferro na Calábria - Itália: um representando as convexidades e concavidades em perfil, o outro as convexidades em planta, ambos construídos a partir de uma legenda onde figuram seis classes de valores do índice de 
convexidade (variação angular/100 metros). A forma de representação cartográfica adotada foi a variação do valor visual da imagem utilizando uma malha de pontos onde figuram caracteres referentes às classes adotadas.

Para se ter uma idéia do volume de trabalho necessário para a elaboração de uma carta de feições mínimas, basta dizer que na maior bacia aqui estudada, com $4,52 \mathrm{Km} 2$ de área, foram mapeadas 1174 unidades elementares de relevo. Isto foi feito sobre uma base cartográfica à escala de 1:10.000, sendo que em cada unidade mapeada foram registrados dados sobre o tipo de forma, a orientação, a declividade e a extensão em área da unidade (em UAs, unidades de área, 1 $u a=2500 \mathrm{~m} 2$ ). Considerando que uma carta topográfica na escala de 1:10.000 deve cobrir uma área de aproximadamente $29,4 \mathrm{Km} 2$, uma carta de feições mínimas com mesma área de abrangência deve apresentar, mantidas as proporções, cer- ca de 7800 unidades de relevo. Claro que, esta estimativa será válida para áreas de estudo sob condições lito-estruturais e climáticas semelhantes.

Para fazer uma síntese estatística morfológicomorfométrica de uma área com cerca de $30 \mathrm{Km} 2$, seriam necessários algumas centenas de milhares de cálculos. O que, na verdade não implica nenhum problema operacional adicional. O maior obstáculo a ser vencido para a produção sistemática deste instrumental refere-se aos procedimentos de confecção do mapa, ainda artesanais, os quais demandariam grande dispêndio de tempo e pessoal especialmente treinado, caso fosse necessário mapear uma grande área. Tais dificuldades poderão ser vencidas quando um sistema digital for capaz de traçar os mapas de feições mínimas, ainda que por um processo semi-controlado.

\section{ABSTRACT}

The chart of minimal features is a special tool destined to offer data about declivity and aspect of slopes, associate with geometric unity forms of the relief, in each kind of "surficial formation". This was possible with the building of the "minimal features model" and its use in the relief cartography. The result is a representative manual analog mosaic of those features unities defined in it, which are differentiate in function of the terrain geometry and kind of water surface flow associate.
This chart will may be usefull for the earth science professionals and ecologists. In this work was used both air photo interpretation (scale 1:25.000), with field control, and topografical map (scale 1:10.000).

\section{BIBLIOGRAFIA}

COLANGELO, A. C. -1989- Carta de Feições Mínimas, XIV Congresso Brasileiro de Cartografia, Gramado - RS, p 375380.

COLANGELO, A. C. -1990- Movimentos de Massa e Evolução Geomorfológica das Vertentes Marginais no Lago de Barragem do Paraibuna-SP, Dissertação de Mestrado, FFLCH-USP, $92 \mathrm{p}$.

COLANGELO, A. C. -1991- Geomorfologia Experimental Aplicada ao Estudo de Estabilidade de Vertentes, IV Simpósio de Geografia Física Aplicada, Porto Alegre - RS, p 267-274.

CRUZ, O. -1974- A Serra do Mar e o Litoral na Área de Caraguatatuba, Teses e Monografias, IGEOG-USP, $p 181$.

DIETRICH, W. E.; WILSON, C. J.; MONTGOMERY, D. R.; MCKEAN, J.; BAUER, R. -1992- Erosion Thresholds and Land Surface Morphology, Geology, vol. 20, Agosto, p 675-679.
HACK, J. J.; GOODLETT, J. C. -1960- Geomorphology and Forest Ecology of a Mountain Region in the Central Appalachians, Unites States Geological Survey Prof Paper, p 347-366.

LIBAULT, A. -1975- Geocartografia, Ed. Nacional - EDUSP, São Paulo, 389 p.RUHE, R. V. -1975- Geomorphology: Geomorphic Processes and Surficial Geolology, Houghten Miflin Company, 246 p.

TROEH, F. R. -1965-Landform Equations Fitted to Countour Maps, American Journal of Sciences, 263:p 616-627. 